\title{
A rock magnetic record of Asian cooling and aridification processes during 1.95-0.40 Ma in the southeastern Chinese Loess Plateau
}

\author{
WU Yi ${ }^{1,2}$, ZHU ZhaoYu ${ }^{2 *}$, QIU ShiFan ${ }^{2} \&$ RAO ZhiGuo ${ }^{3}$ \\ ${ }^{1}$ Key Laboratory of Marginal Sea Geology, South China Sea Institute of Oceanology, Chinese Academy of Sciences, Guangzhou 510301, China; \\ ${ }^{2}$ Key Laboratory of Marginal Sea Geology, Guangzhou Institute of Geochemistry, Chinese Academy of Sciences, Guangzhou 510640, China; \\ ${ }^{3}$ Key Laboratory of Western China's Environment Systems (Ministry of Education), Lanzhou University, Lanzhou 730000, China
}

Received September 14, 2012; accepted February 6, 2013; published online May 3, 2013

\begin{abstract}
The southeastern Chinese Loess Plateau is the terminal deposition area of dusts transported by the East Asian winter monsoon and the frontal area penetrated by the East Asian summer monsoon, and thus a climate sensitive region. This paper reports a rock magnetic study of a Quaternary loess-paleosol section in such a region. We tried to reconstruct the paleoclimate evolution history in the region during 1.95-0.40 Ma with magnetic parameters. The results show a general up-section decreasing trend of the ratio of HIRM/(SIRM-IRM $\left.{ }_{100 \mathrm{mT}}\right)$, indicating a long-term decreasing trend of hematite coercivities in the deposits, which can be mainly related to the cooling and aridification trend of the environment in interglacial depositional area and glacial dust source region. The ratio, $\chi_{\text {If }} / \chi_{\text {ARM }}$, widely used to reflect the variations of magnetic mineral grain size, manifests a long-term increasing trend of the magnetic mineral grain size and tends to indicate an overall weakening trend of the East Asian summer monsoon that controlled the pedogenic intensity. Although the regional multi-segmented paleoclimatic records revealed by several magnetic parameters in our study, the long-term Asian cooling and aridification trend inferred here is of global correlation significance.
\end{abstract}

Chinese Loess Plateau, eolian deposits, hematite, paleoclimate, environmental magnetism

Citation: Wu Y, Zhu Z Y, Qiu S F, et al. A rock magnetic record of Asian cooling and aridification processes during $1.95-0.40$ Ma in the southeastern Chinese Loess Plateau. Chin Sci Bull, 2013, 58: 3636-3644, doi: 10.1007/s11434-013-5775-5

As an important carrier of paleoclimate and paleoenvironment information, the East Asian eolian deposits have been extensively studied over the past thirty years [1-7]. Particularly, a good correlation between the events extracted from the eolian deposits and global sedimentary and tectonic events [2,5-11] renders the loess-paleosol sequence an important proxy of the late Cenozoic climate and environments.

The thick eolian deposits in East Asian interior can be dated back to at least Oligocene-Miocene boundary [10,12,13], providing strong evidence for the existence of a vast Asian interior desert. Recently, Hao et al. [14,15] applied rock magnetic parameters of eolian deposits since late Miocene to interpret paleoenvironment changes. The long-term trend of the magnetic signals are similar to the long-term changes of the deep-sea oxygen isotope values [16]. The studies of

*Corresponding author (email: zhuzy@gig.ac.cn)
Deng et al. on the north Jingbian section [17] and the central Jiaodao section [18] in the Chinese Loess Plateau are only limited to the Quaternary loess-paleosol sequence, but they systematically extracted a relatively complete record of the East Asian monsoon climate evolution in the entire Quaternary period. In this study, we focus on the southeastern Chinese Loess Plateau, report the environmental magnetic signatures extracted from the eolian deposits in the Lantian Basin and a reconstruction of paleoclimate changes during 1.95-0.40 Ma. We found that the long-term trend of cooling and aridification in Asia is well correlated with global climate changes in the same period.

\section{Sampling and methods}

The Yushan section $\left(34.23^{\circ} \mathrm{N}, 109.48^{\circ} \mathrm{E}\right)$ is located in the 
territory of Yushan Town, Lantian County, Shaanxi Province. The top of the section, which is located on a broken loess tableland (Hengling Plateau) is about $905 \mathrm{~m}$ above sea leval, while the altitude of the base of the section, which is located on a gully surface, is about $815 \mathrm{~m}$. The section is all exposed with a thickness of about $80 \mathrm{~m}$ for the Quaternary loess-paleosol sequence, including several carbonate nodule layers of thicknesses ranging from 0.3 to $3.0 \mathrm{~m}$ in the $\mathrm{Wu}-$ cheng Loess Formation [1]. From the top of the outcrop to the bottom gully, we measured a continuous loess section in nearly NNW-SSE direction on a valley-side slope. This section includes the loess-paleosol units from L27 to L5. The units L15-L5 have been described before [19]. The sequence below L15 is usually easy to recognize in the field, especially in the southern Chinese Loess Plateau. Below the silty loess unit L15 in the Yushan section, at least 12 dark red paleosol units have been clearly identified. Together with paleomagnetic results (which will be reported in another article in detail), description and classification of the units are shown in Figure 1. Samples were collected from layers without carbonate nodules from the outcrop. Therefore, in the lithology column (Figure 1) no carbonate nodule

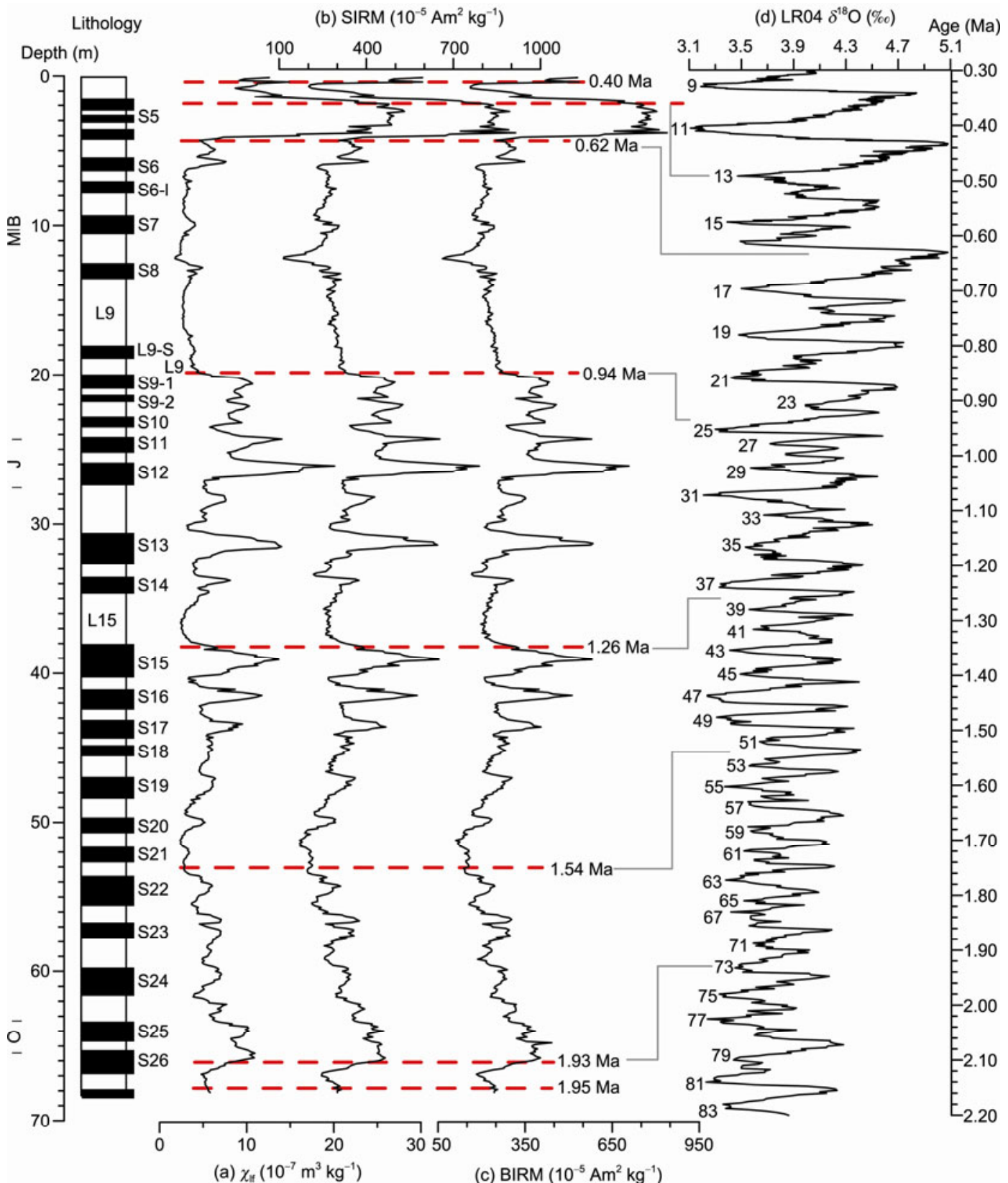

Figure 1 Column of the loess-paleosol sequence of the Yushan section, and its magnetic records and their correlations with the deep-sea oxygen isotope curve "LR04" [20]. Warm deep-sea oxygen isotope stages are oddly numbered in "LR04". Part of the magnetic records of 0-38.8 m have been discussed in [19]. 
layers were marked. We collected a total of 681 powder samples with a sampling interval of $10 \mathrm{~cm}$. The actually controlled thickness of the section is $68.10 \mathrm{~m}$.

The experimental method is basically the same as described in [19]. The magnetic parameters are calculated as [21,22]:

Frequence-dependent magnetic susceptibility, $\chi_{\mathrm{fd}}=\chi_{\mathrm{lf}}-\chi_{\mathrm{hf}}$, $\mathrm{BIRM}=-\mathrm{IRM}_{-300 \mathrm{mT}}$;

High coercivity isothermal remanence, HIRM $=0.5 \times$ $\left(\right.$ SIRM+IRM $\left._{-300 \mathrm{mT}}\right)$;

$S$ ratio, $S$-ratio $=$ BIRM/SIRM.
Among them, $\chi_{\mathrm{lf}}$ and $\chi_{\mathrm{hf}}$ represent the magnetic susceptibility measured at frequencies of 0.47 and $4.7 \mathrm{kHz}$ respectively. SIRM (saturation isothermal remanent magnetization) denotes the IRM intensity acquired at $1000 \mathrm{mT}$ DC field. IRM $_{-300 \mathrm{mT}}$ is the intensity of SIRM after exposure of samples at a back field of $300 \mathrm{mT}$. In Figure 2, $\mathrm{IRM}_{100 \mathrm{mT}}$ represents the IRM intensity acquired at $100 \mathrm{mT}$ DC field. For samples from below $38.80 \mathrm{~m}$, the IRMs were acquired at fields following the sequence of 20,50,100, $1000 \mathrm{mT}$ and back field $300 \mathrm{mT}$. S-ratio and HIRM are often used to assess the relative/absolute content of antiferromagnetic minerals

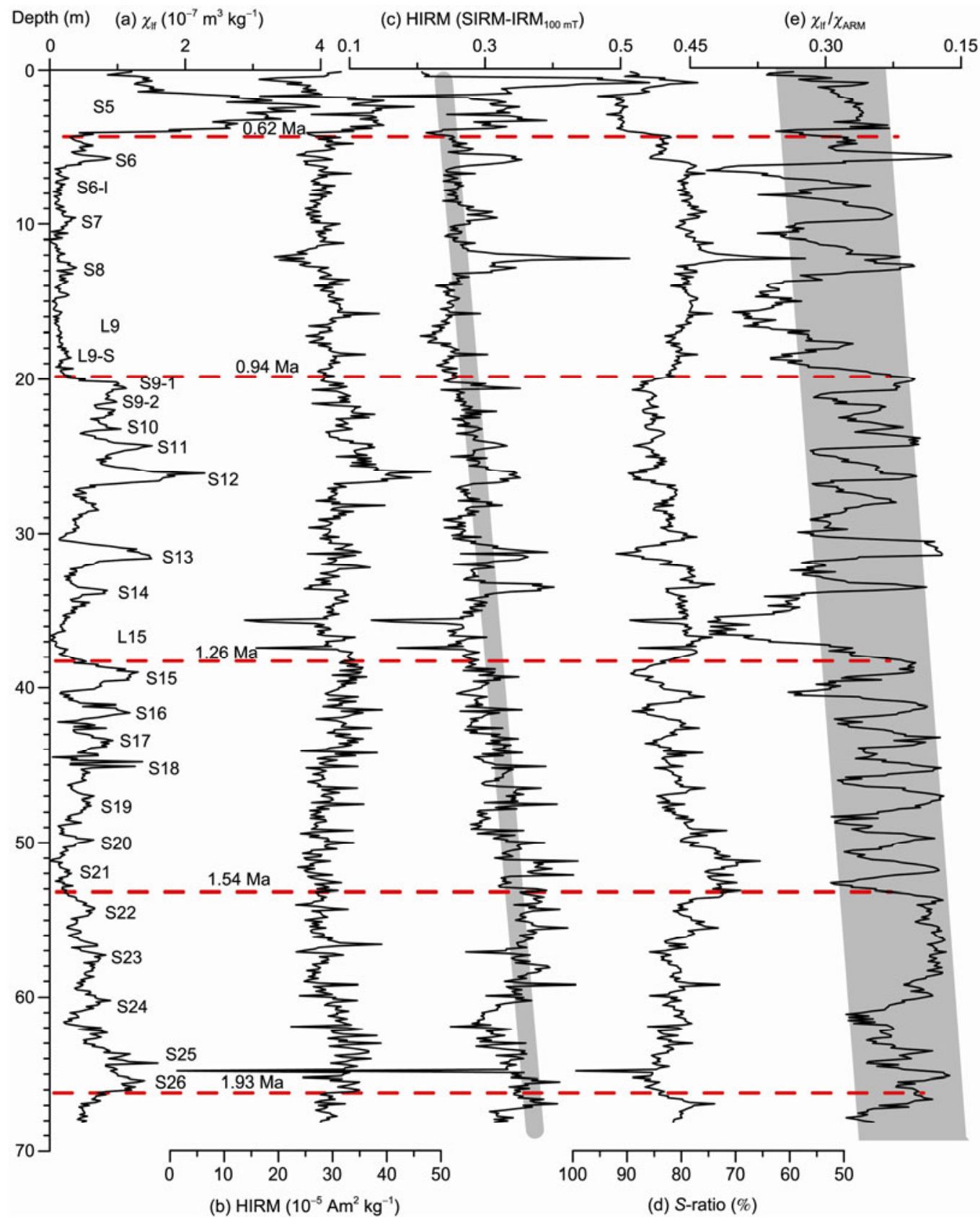

Figure 2 Additional magnetic records from the loess-paleosol sequence in the Yushan section. Gray bars indicate the general trend of curves. Part of the magnetic records of 0-38.8 $\mathrm{m}$ have been discussed in [19]. 
(especially hematite) [21,22]. SIRM reflects the contribution of partial ferrimagnetic minerals (magnetite/ maghemite) and imperfect antiferromagnetic minerals [21]. Besides, SIRM is influenced by the pedogenic ferrimagnetic grains to a larger extent [17]. Because goethite is far from saturation at $1000 \mathrm{mT}$ [23], hematite plays a leading role in the antiferromagnetic signal involved in the above parameters. The significance of HIRM/(SIRM-IRM $\left.{ }_{100 \mathrm{mT}}\right)$ will be stated in the discussion part.

\section{Results}

The ratios of $\mathrm{IRM}_{300 \mathrm{mT}} / \mathrm{SIRM}$ of 18 samples from individual loess and paleosol unit are all greater than $80 \%$, while a sample from S5 even reaches $95.99 \%$ (Figure 3). At fields greater than $300 \mathrm{mT}$, the IRM acquisition curves of loess samples tend to be more inclined than those of paleosol samples on the whole (Figure 3(a),(c)). In addition, the remanent magnetic coercivities of loess samples are larger than those of paleosol samples (Figure 3(b),(d)). Combined with previously reported thermomagnetic curves of loess and paleosol samples [19], these all indicate that the main magnetic carriers in Yushan loess-paleosol section include ferrimagnetic magnetite and maghemite and antiferromagnetic hematite and goethite. In Figure 4, the Day diagram displays that 12 samples are distributed in the range of pseudo single domain (PSD), which indicates that the mean grain size is constant. However, the projections of loess and paleosol samples in the figure are notably different, which reveals that there might be significant differences in the grain sizes of magnetic grains. Similar characteristics are also seen in the Jingbian section [17] and the Jiaodao section [18].

The rock magnetic records, i.e., the magnetic susceptibility (Figures 1(a),2(a)), IRM (Figure 1(b),(c)) and the grain
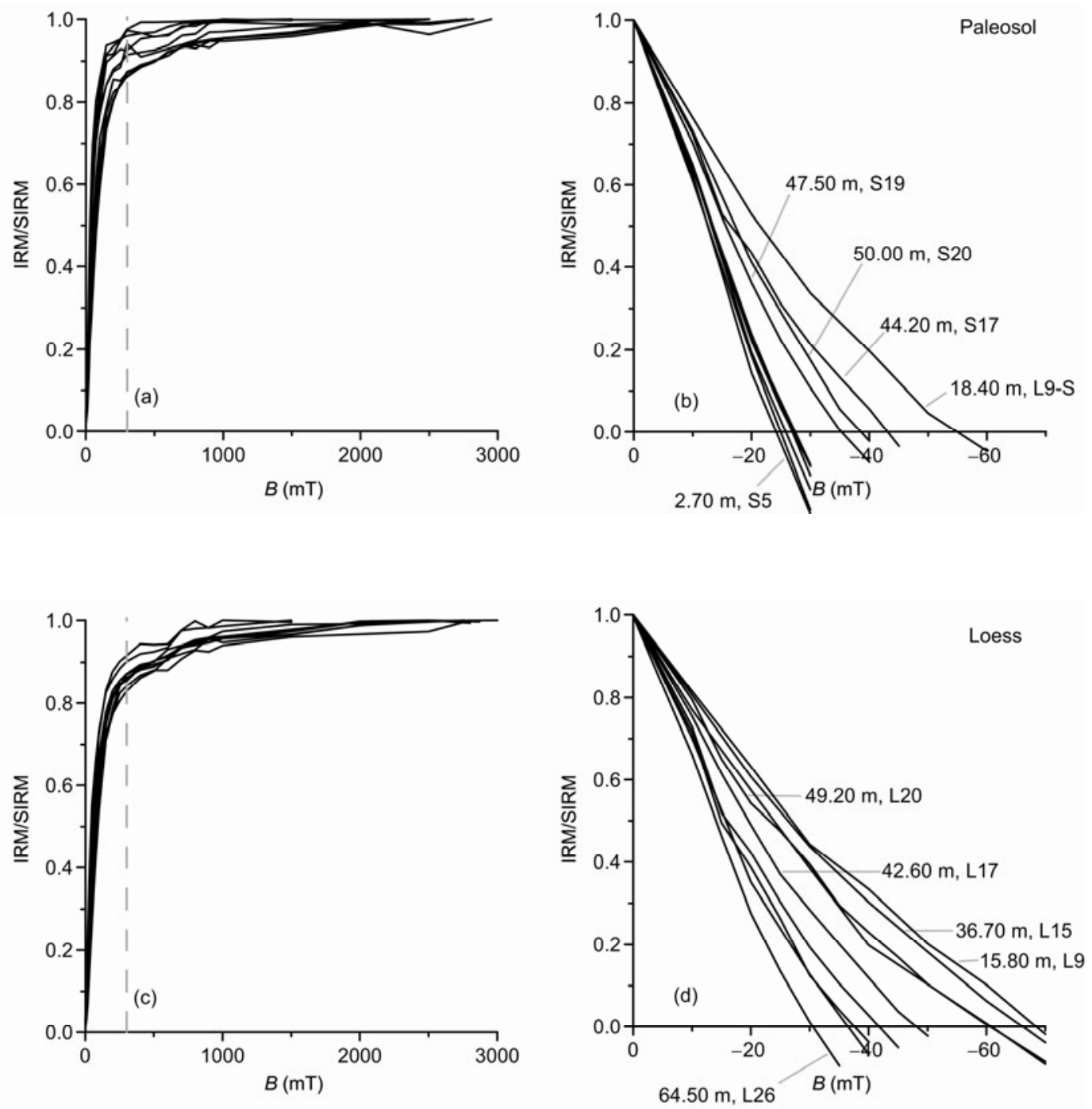

Figure 3 IRM acquisition and back field demagnetization curves of typical samples from paleosol ((a), (b)) and loess units ((c), (d)), respectively. The gray dash lines in (a) and (c) indicate that the magnetic field is $300 \mathrm{mT}$. The maximum magnetic field applied is $1500-3000 \mathrm{mT}$. 


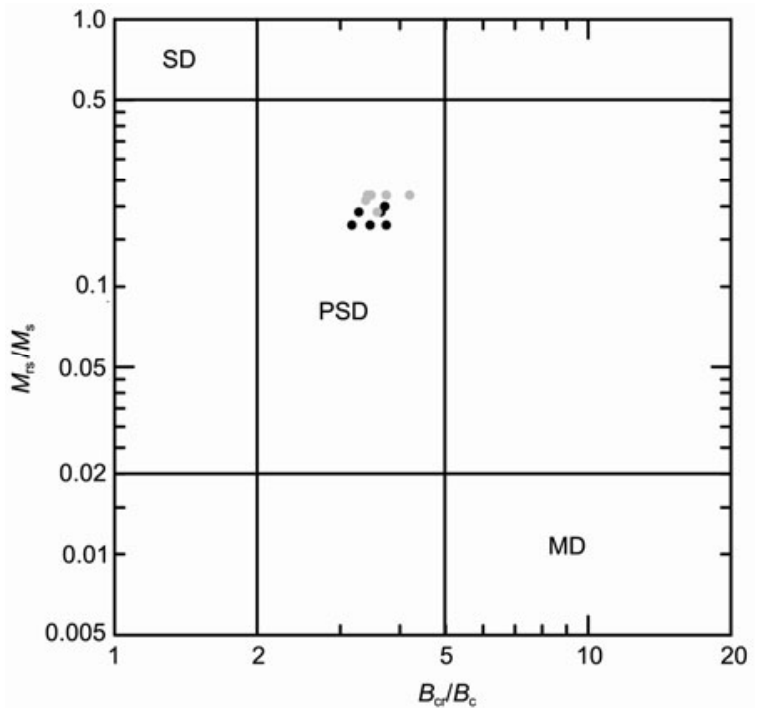

Figure 4 A Day diagram [24,25] for selected loess (gray) and paleosol (black) samples. SD, Single domain; PSD, Pseudo single domain; MD, Multidomain.

size parameter (Figure 2(e)) of 681 samples of the entire section all clearly reflect the differences between the glacial loess deposits and interglacial paleosol deposits. Peaks and valleys of the first four curves $\left(\chi_{\mathrm{lf}}, \chi_{\mathrm{fd}}, \mathrm{SIRM}, \mathrm{BIRM}\right)$ correspond well with each other in detail and general evolution trend, representing a consistent pattern. In comparison, $\chi_{\mathrm{lf}} /$ $\chi_{\text {ARM }}($ Figure $2(e)$ ), which reflects grain size variations, more clearly manifests the cyclic variations during glacial and interglacial periods, especially the segments before and after the lower silty loess unit L15 (L22-S15 and S14-S9-1). In addition, the grain size values of L15 and S9-1-S6 in loess units are obviously higher than those in the other loess units (Figure 2(e)).

The curves of HIRM and $S$-ratio and ratio parameter $\mathrm{HIRM} /\left(\mathrm{SIRM}-\mathrm{IRM}_{100 \mathrm{mT}}\right)$ used in this study also show relative variations for the glacial and interglacial deposits. But obviously the curves are not as clear as those of the other parameters. The smoothing levels of the curves all are poorer. However, in terms of manifesting the variation trend, there are consistent turning points, for example the points at levels within L22, L15, L9, etc. (Figure 2). There is no significant correlation between HIRM/(SIRM-IRM $100 \mathrm{mT})$ and HIRM in the Yushan section. Although both HIRM, and HIRM/ $\left(\mathrm{SIRM}_{\mathrm{IRM}} \mathrm{I}_{100 \mathrm{mT}}\right)$ do not vary dramatically (Figure $5(\mathrm{~b})$ ), it is still easy to recognize the general decreasing trend upward the whole section (Figure 2(c)), which is similar to the variation of the grain size parameter, $\chi_{\mathrm{lf}} / \chi_{\mathrm{ARM}}$.

\section{Discussion}

\subsection{Long-term evolution trend revealed by HIRM/ (SIRM-IRM $100 \mathrm{mT})$ and $\chi_{\text {If }} / \chi_{\mathrm{ARM}}$}

Recently, Liu et al. [26] further evaluated the denotative meaning of $S$-ratio and HIRM based on the magnetic characteristic analysis on the synthetic Al-substituted hematite/ goethite samples. The research showed that the aluminum substitute existing in the magnetic mineral lattice would lead to substantial variations of remanent magnetic coercivities and this difference would result in multiple solutions of quantitative parameters $S$-ratio and HIRM. Therefore, they put forward to use the stability of $L$-ratio $\left(\mathrm{IRM}_{\mathrm{AF} @ 300 \mathrm{mT}} /\right.$ $\mathrm{IRM}_{\mathrm{AF} @ 100 \mathrm{mT}}$, denominator and numerator respectively represent the obtained IRM at $1000 \mathrm{mT}$ followed by peak alternating field demagnetization at 100 and $300 \mathrm{mT}$ ), or the stability of an equivalent parameter HIRM/[0.5 $\times(\mathrm{SIRM}+$ IRM $_{-100 \mathrm{mT}}$ )] to measure the validity of $S$-ratio and HIRM as content indices of antiferromagnetic minerals. The study indicates that under the background of strong ferrimagnetic signal, when $L$-ratio is relatively stable, HIRM can clearly reflect the antiferromagnetic mineral content. If $L$-ratio fluctuates greatly, it indicates that there is a significant variation in coerciveity of antiferromagnetic minerals related to
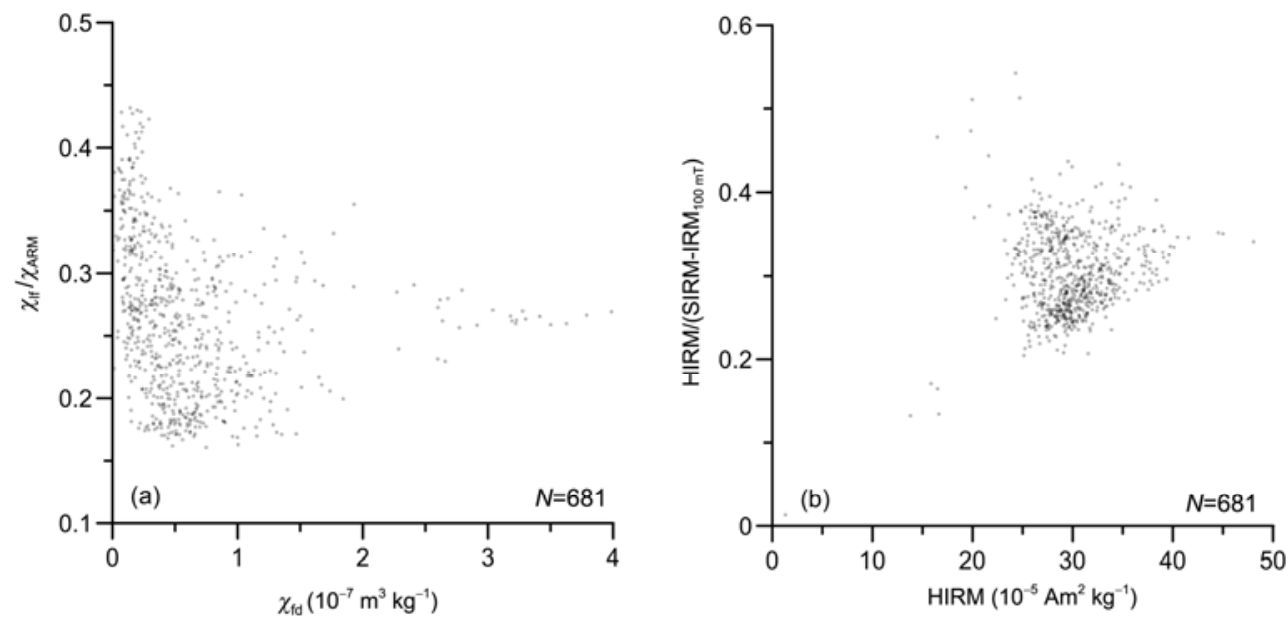

Figure 5 Plots of $\chi_{\mathrm{fl}} / \chi_{\mathrm{ARM}}$ versus $\chi_{\mathrm{fd}}(\mathrm{a})$, and HIRM/(SIRM-IRM $\left.{ }_{100 \mathrm{mT}}\right)$ versus HIRM (b). 
variability in depositional sources. HIRM/(SIRM-IRM $\left.{ }_{100 \mathrm{mT}}\right)$ in this study can be regarded as the equivalent substitute parameter of $\mathrm{HIRM} /\left[0.5 \times\left(\mathrm{SIRM}_{+} \mathrm{IRM}_{-100 \mathrm{mT}}\right)\right]$ or $L$-ratio proposed by Liu et al. [26], for evaluating the whole section's antiferromagnetic mineral coerciveity with weak magnetism. Among them, HIRM is equivalent to $\mathrm{IRM}_{\mathrm{AF} @ 300 \mathrm{mT}}$, and $\left(\mathrm{SIRM}-\mathrm{IRM}_{100 \mathrm{mT}}\right)$ to $\mathrm{IRM}_{\mathrm{AF} @ 100 \mathrm{mT}}$.

Figure 5(b) displays that variation of the parameter HIRM/ $\left(\mathrm{SIRM}_{\mathrm{IRM}} \mathrm{I}_{100 \mathrm{mT}}\right)$ is not significant, which indicates that the dust source may be relatively stable. It also indicates that the $S$-ratio and HIRM are still applicable to the conventional interpretation of the content of antiferromagnetic mineral with the main mineral composition of hematite [26]. Compared with the loess units, the paleosol units show a more obvious fluctuation of the ratio of HIRM/(SIRM$\mathrm{IRM}_{100 \mathrm{mT}}$ ) (Figure 2(c)), which embodies the influence of pedogenic hematite. This is very similar to the Jingbian section, which is adjacent to the Mu Us Desert, especially in terms of the curves of $\mathrm{SIRM}_{100 \mathrm{mT}} / \mathrm{SIRM}_{30 \mathrm{mT}}$ and $\mathrm{SIRM}_{100 \mathrm{mT}} /$ $\mathrm{SIRM}_{60 \mathrm{mT}}$ [17] that reflect the long-term cooling and aridification process recorded in the Jingbian section. We can see an overall up-section decreasing trend of the parameter of HIRM/(SIRM-IRM $100 \mathrm{mT}$ ) (Figure 2(c)). However, the long-term evolution characteristics cannot be identified from the curves of HIRM and S-ratio (Figure 2(b), (d)), which indicates that this phenomenon is not caused by variations of the relative content of magnetic minerals. The variations of hematite coercivities are unlikely caused by defects of mineral lattice because it is not realistic to generate a relatively consistent long-term evolution trend. We interpret this as mainly due to grain size variations related to the environmental transition during the formation period of the loess-paleosol sequence.

Due to the different climate conditions of dust deposition during the glacial and interglacial periods, the contents of pedogenic hematite in the depositional area are definitely different. However, the HIRM/(SIRM-IRM $100 \mathrm{mT})$ curve shows that its difference between loess and paleosol is less significant than the other magnetic parameters, for example, $\chi_{\mathrm{lf}}$. This might be relevant to a large proportion of detrital hematite in the loess units [27]. Due to the color rendering characteristics of hematite, the color variations of eolian deposits observed by eyes in the field, especially the variations from dark red to reddish brown in temporal and spatial scale relevant to paleosol units can not easily be attributed to variations of the hematite content [28]. Hematite plays a leading role in the antiferromagnetic mineral in loess/paleosol deposits [29], particularly in moderately weathered loess units, in which hematite of detrital origin is dominant [30]. In comparison, hematite of pedogenic origin is dominant in the paleosol units. Combined with geochemical results, Bloemendal and Liu [31] speculated that the peak values of HIRM indicated there are pedogenic hematite in S1 and S5 of the Luochuan section and S13, S14 and S15 of the Duanjiapo section. Even for the Jingbian section, adja- cent to the Mu Us Desert, its generated hematite in the paleosol unit is considered to be dominated by pedogenic origin, while hematite in the loess unit is dominated by detrital origin [17]. Due to the special geographical position of the Jingbian section, the pedogenesis intensity of deposits during the glacial period might be extremely weak, so the pedogenic hematite in the loess unit is nearly negligible. On the other hand, for the large cross section from north to south on the Chinese Loess Plateau is influenced by the gradient variation of zonal climate, the differences between loess and paleosol units recorded by the magnetic parameters seem to weaken. This feature is quite obvious in SIRM curves of the Jingbian section [17], Luochuan section [31] and Duanjiapo section [31]. The oscillation amplitudes of peak-valley cycle of the latter two sections' curves are obviously less significant, which is related to the contemporaneous southward weakening of glacial cooling and aridification degree. The Yushan section, to the southeast of the Duanjiapo section might be influenced by summer monsoon even during the glacial loess depositional period and experienced some degree of pedogenesis, which would generate a few hematite particles. We infer that the pedogenic hematite in the loess units is still much less than the detrital origin hematite. The long-term variation characteristics of hematite coercivities in the paleosol and loess units of the Yushan section indicate that the climate conditions in the interglacial depositional area and glacial source region have experienced a long-term and sluggish variation. Furthermore, in fact, the paleosol unit and loess unit show relatively obvious fluctuations. However, they both present a longterm decreasing trend through the respective observation of the sequence of HIRM/(SIRM-IRM $\left.{ }_{100 \mathrm{mT}}\right)$ in the interglacial paleosol unit and the glacial loess unit. The various evolution patterns at some stages (major ones at the turning points of L25, L22, L15 and S5) indicate that the whole climate was developing into a colder and drier one. This reflects regional responses of the entire environment in the Asian interior desert region to the global ice sheet increase in the late Cenozoic Era [16,20].

In comparison, $\chi_{\mathrm{If}} / \chi_{\mathrm{ARM}}$ can not only reflect the difference between the glacial period and interglacial period more accurately than other parameters (Figures 1 and 2) but also present a similar long-term trend as shown in Figure 2(c). This is consistent with the long-term increasing variation trend of the $\delta^{18} \mathrm{O}$ values shown by the integration curve of the global deep-sea oxygen isotope [20] (Figure 1(d)). Because our study section is located in the front area of warm and wet East Asian summer monsoon from ocean into Asian interior, the glacial period and interglacial period was alternately examplified as highs and lows in the rock magnetic curves. From the Jiaodao section in the hinterland of the Chinese Loses Plateau (see Figure 6 in [18]), the contrast between the glacial period and interglacial period as represented by $\chi_{\mathrm{lf}} / \chi_{\mathrm{ARM}}$ is more significant, which might be related to the different regional climates under the interglacial 
warm and wet conditions and mainly controlled by the zonal gradient effect of the summer monsoon on the Chinese Loess Plateau [27]. Variations of the ratio of $\chi_{\mathrm{lf}} / \chi_{\mathrm{ARM}}$ are originated from two competitive factors $[18,32]$. One is generated from the ultrafine superparamagnetic (SP) grains of pedogenic origin which is relevant to the summer monsoon intensity. The other one is generated from the PSD/MD magnetite grains of detrital origin which is relevant to the winter monsoon intensity. In Figure $5(\mathrm{a}), \chi_{\mathrm{If}} / \chi_{\mathrm{ARM}}$ and $\chi_{\mathrm{fd}}$ represent a relatively obvious, negative correlation. This indicates that the increasing trend of $\chi_{\mathrm{lf}} / \chi_{\mathrm{ARM}}$ upward the section, to a larger extent, embodies the background trend of gradually weakening of the summer monsoon at 1.95-0.40 Ma. The input of coarse-grained magnetite grains of detrital origin in dust source region can result in the increase of $\chi_{\mathrm{lf}}$. With the influence of weakening summer monsoon, the relatively decreasing magnetite content generated during the pedogenesis process in depositional area lead to the decease of $\chi_{\text {ARM. }}$. The superimposed effect of both manifests the increasing trend of $\chi_{\mathrm{lf}} / \chi_{\mathrm{ARM}}$, namely, the increasing trend of grain size. The ice sheet in the northern hemisphere during late Cenozoic Era tended to increase. Along with drop of global sea level, the temperature reduction would lead to the weakening of moisture capacity. Although the seasonal precipitation possibly shows an increasing trend, the East Asian summer monsoon under its direct influence would manifest a strong overall weakening trend [33]. In addition to the comparison and published environmental magnetic results $[14,15,17,18,34,35]$, non-magnetic evidence from loess sections also clearly indicates the long-term variation trend of the Quaternary climate, for example, strontium isotope records from the Luochuan section [36] and the Jingchuan section [37]. Ao et al. [38,39] successfully extracted the severer aridification signal since the Pleistocene period from the fluvial-lacustrine facies sediments in the Nihewan Basin, which also indirectly proved the potential of East Asian continental sediments to reconstruct the contemporaneous global paleoclimate.

\subsection{Significance of section variations of multiple magnetism parameters}

The reconstructed paleoclimatic changes resulted from various rock magnetic proxies always manifests a periodic evolution model. However, there are obvious differences between the timelines of important variations, which are often attributed to regional control factors. The significant characteristics of the magnetic parameters $\left(\chi_{\mathrm{lf}}, \mathrm{SIRM}, \mathrm{BIRM}\right.$, $\chi_{\mathrm{fd}}, \mathrm{HIRM}, S$-ratio) from the Yushan section show a staged variation trend, reflecting the alternation direction of secondary regional climate. The major turning points are about at 1.54, 1.26, 0.94 and $0.62 \mathrm{Ma}$ (Figures 1 and 2) while these curves are not simply monotonic increasing or decreasing. However, there are consistent low values at L22 ( 1.54 Ma), L15 ( 1.26 Ma) and L9-L6 (0.94-0.62 Ma). The low values around L22 are shown in the long-term variation pattern of the curves, namely, the lows between S26-S15 of the section. There are no similar characteristics in the records from other typical sections. The low values in the latter two segments (L15 and L9-L6) are closely related to the upper and lower silty loess units (L9 and L15), which might be due to changes of the dust origin and transportation pathways caused by pulsed growth events of the Qinghai-Tibet Plateau [17-19,40-42]. The magnetic properties of segment L9-L6 show that after L9 deposition, the environment of about 0.32 Myr in the deposition area was in an overall stable condition, a relatively cold and arid climate. In addition to the consistent turning points at L15, L9 and S5, HIRM/ $\left(\mathrm{SIRM}-\mathrm{IRM}_{100 \mathrm{mT}}\right)$ and $\chi_{\mathrm{lf}} / \chi_{\mathrm{ARM}}$ also have an obvious valley/ peak around L25. In fact, this turning point is also slightly embodied in the $\chi_{\mathrm{lf}}, \chi_{\mathrm{fd}}$ and HIRM curves, which indicates that stage L25 seems to be the maximum of climatic deterioration since $1.93 \mathrm{Ma}$. The loess depositional stage seems to have relevant manifestation in the other regions in Chinese Loess Plateau, for example, sections of Lingtai in the south, Baoji and Puxian in the east. Their grain size records all indicate a persistent period of colder and drier glacial climate condition [5]. Furthermore, multiple magnetic parameters from the Duanjiapo section also show an obvious low [31].

It must be pointed out that, some units of eolian deposits similar to the upper silty unit L9 are frequently regarded as accretion under obvious cold and arid climate conditions according to field observation and regular experimental analysis, but they might potentially record abundant details of cold-warm and dry-wet climate variations [43]. Inferred from the differences between the existing results from this section and other typical sections, loess deposition in front of the Qinling Mts. might response to the regional neotectonic activities and local vegetation variations [19]. Using the conventional magnetic susceptibility and quartz grain size methods to synthetically analyze the monsoon evolution history of the Zhaojiachuan and Lingtai sections in the south central Chinese Loess Plateau highlights a key turning period at 1.25 $\mathrm{Ma}(\sim \mathrm{L} 15)$ in the Quaternary period [6], which matches up with the southward invasion event of the $\mathrm{Mu}$ Us Desert. This event is reconstructed from sedimentary records in the northern Jingbian section around 1.2 Ma [44]. However, it is difficult to find out obvious traces in the vegetational succession $[33,45]$. The similarities or differences of these reconstruction results are doomed to have significant correlation with the chronology framework establishment of the studied sections and the restriction mechanisms of alternation proxies. But the particular sedimentary backgrounds in different areas are also important factors. The Lantian Basin, where the Yushan section is located is adjacent to the northern slope of the Qinling Mts., so there might be obvious amplification effect in the depositional and pedogenic processes due to pulsed events of the adjacent mountains, which would cover the regional record of 
response to global climatic processes to a certain extent.

\section{Conclusions}

A long-term variation trend of $\mathrm{HIRM} /\left(\mathrm{SIRM}-\mathrm{IRM}_{100 \mathrm{mT}}\right)$ and $\chi_{\text {If }} / \chi_{\text {ARM }}$ from the Yushan section may jointly indicate the records of global cooling and aridification processes during 1.95-0.40 Ma. HIRM/(SIRM-IRM $100 \mathrm{mT})$ is related to the variations of hematite coercivities in deposits of both detrital and pedogenic origins and $\chi_{\mathrm{If}} / \chi_{\mathrm{ARM}}$ is usually used to reflect the pedogenic (soil forming) intensity. Under the background of long-term variations, multiple magnetic curves can also be used to reconstruct the trend of secondary regional paleoclimatic evolution events, and timelines of these important events are at 1.54 Ma (L22), 1.26 Ma (L15), $0.94 \mathrm{Ma}(\mathrm{L} 9)$ and 0.62 Ma (L6), respectively.

This work was supported by the National Basic Research Program of China (2010CB833405) and the National Natural Science Foundation of China (41102115 and 40930106). The authors are grateful to two anonymous referees for critical comments and valuable suggestions and Dr. Tan Xiaodong for polishing English.

1 Liu T S. Loess and the Environment. Beijing: China Ocean Press, 1985

2 Kukla G, Heller F, Liu X M, et al. Pleistocene climates in China dated by magnetic susceptibility. Geology, 1988, 16: 811-814

3 Zhou L P, Oldfield F, Wintle A G, et al. Partly pedogenic origin of magnetic variations in Chinese loess. Nature, 1990, 346: 737-739

4 Liu T S, Ding Z L. Chinese loess and paleomonsoon. Annu Rev Earth Planet Sci, 1998, 26: 111-145

5 Ding Z L, Derbyshire E, Yang S L, et al. Stacked 2.6-Ma grain size record from the Chinese loess based on five sections and correlation with the deep-sea $\delta^{18} \mathrm{O}$ record. Paleocenography, 2002, 17, doi: 10. 1029/2001PA000725

6 Sun Y B, Clemens S C, An Z S, et al. Astronomical timescale and palaeoclimatic implication of stacked 3.6-Myr monsoon records from the Chinese Loess Plateau. Quat Sci Rev, 2006, 25: 33-48

7 Deng C L, Liu Q S, Pan Y X, et al. Environmental magnetism of Chinese Loess-Plateau sequences (in Chinese). Quat Sci, 2007, 27: 193-209

8 Guo Z T, Liu T S, Fedoroff N, et al. Climate extremes in Loess of China coupled with the strength of deep-water formation in the North Atlantic. Glob Planet Change, 1998, 18: 113-128

9 An Z S, Kutzbach J E, Prell W L, et al. Evolution of Asian monsoons and phased uplift of the Himalaya-Tibetan plateau since Late Miocene times. Nature, 2001, 411: 136-144

10 Guo Z T, Ruddiman W F, Hao Q Z, et al. Onset of Asian desertification by $22 \mathrm{Myr}$ ago inferred from loess deposits in China. Nature, 2002, 416: 159-163

11 Nie J S, King J W, Fang X M. Correlation between the magnetic susceptibility record of the Chinese aeolian sequences the marine benthic oxygen isotope record. Geochem Geophys Geosyst, 2008, 9: Q12026

12 Qiang X K, An Z S, Song Y G, et al. New eolian red clay sequence on the western Chinese Loess Plateau linked to onset of Asian desertification about 25 Ma ago. Sci China Ser D-Earth Sci, 2011, 54: 1479-1488

13 Sun J M, Ye J, Wu W Y, et al. Late Oligocene-Miocene mid-latitude aridification and wind patterns in the Asian interior. Geology, 2010, 38: $515-518$
14 Hao Q Z, Oldfield F, Bloemendal J, et al. The magnetic properties of loess and paleosol samples from the Chinese Loess Plateau spanning the last 22 million years. Palaeogeogr Palaeoclimatol Palaeoecol, 2008, 260: 389-404

15 Hao Q Z, Oldfield F, Bloemendal J, et al. The record of changing hematite and goethite accumulation over the past $22 \mathrm{Myr}$ on the Chinese Loess Plateau from magnetic measurements and diffuse reflectance spectroscopy. J Geophys Res, 2009, 114: B12101

16 Zachos J, Pagani M, Sloan L, et al. Trends, rhythms, and aberrations in global climate $65 \mathrm{Ma}$ to present. Science, 2001, 292: 686-693

17 Deng C L, Shaw J, Liu Q S, et al. Mineral magnetic variation of the Jingbian loess/paleosol sequence in the Northern Loess Plateau of China: Implications for Quaternary development of Asian aridification and cooling. Earth Planet Sci Lett, 2006, 241: 248-259

18 Deng C L, Vidic N J, Versub K L, et al. Mineral magnetic variation of the Jiaodao Chinese loess/paleosol sequence and its bearing on long-term climatic variability. J Geophys Res, 2005, 101: B03103

19 Wu Y, Zhu Z Y, Rao Z G, et al. Mid-late Quaternary loess-paleosol sequence in Lantian's Yushan, China: An environmental magnetism approach and its paleoclimatic significance. Chin Sci Bull, 2010, 55: 2989-3000

20 Lisiecki L, Raymo M E. A Pliocene-Pleistocene stack of 57 globally distributed benthic $\delta^{18} \mathrm{O}$ records. Paleocenography, 2005, 20: PA1003

21 Thompson R, Oldfield F. Environmental Magnetism. London: Allen and Unwin, 1986. 1-227

22 Evans M E, Heller F. Environmental Magnetism: Principles and Applications of Enviromagnetics. San Diego: Academic Press, 2003. 1-299

23 Rochette P, Mathe P E, Esteban L, et al. Non-saturation of the defect moment of goethite and fine-grained hematite up to 57 Tesla. Geophys Res Lett, 2005, 32: L22309

24 Day R, Fuller M, Schmidt V A. Hysteresis properties of titanomagnetites: Grain-size and compositional dependence. Phys Earth Planet Inter, 1977, 13: 260-267

25 Dunlop D J. Theory and application of the Day plot $\left(M_{\mathrm{rs}} / M_{\mathrm{s}}\right.$ versus $\left.H_{\mathrm{cr}} / H_{\mathrm{c}}\right)$ : 1 . Theoretical curves and tests using titanomagnetite data. J Geophys Res, 2002, 107: 2056

26 Liu Q S, Roberts A P, Torrent J, et al. What do the HIRM and S-ratio really measure in environmental magnetism? Geochem Geophys Geosyst, 2007, 8: Q09011

27 Bloemendal J, Liu X M, Sun Y B, et al. An assessment of magnetic and geochemical indicators of weathering and pedogenesis at two contrasting sites on the Chinese Loess Plateau. Palaeogeogr Palaeoclimatol Palaeoecol, 2008, 257: 152-168

28 Balsam W, Ji J F, Chen J. Climatic interpretation of the Luochuan and Lingtai loess sections, China, based on changing iron oxide mineralogy and magnetic susceptibility. Earth Planet Sci Lett, 2004, 223 : 335-348

29 Liu Q S, Torrent J, Maher B A, et al. Quantifying grain size distribution of pedogenic magnetic particles in Chinese loess and its significance for pedogenesis. J Geophys Res, 2005, 110: B11102

30 Evans M E, Heller F. Magnetic enhancement and palaeoclimate: A study of a loess/palaeosol couplet across the Loess Plateau of China. Geophys J Int, 1994, 117: 257-264

31 Bloemendal J, Liu X M. Rock magnetism and geochemistry of two plio-pleistocene Chinese loess-palaeosol sequences-Implications for quantitative palaeoprecipitation reconstruction. Palaeogeogr Palaeoclimatol Palaeoecol, 2005, 226: 149-166

32 Deng C L. Paleomagnetic and mineral magnetic investigation of the Baicaoyuan loess-paleosol sequence of the western Chinese Loess Plateau over the last glacial-interglacial cycle and its geological implications. Geochem Geophys Geosyst, 2008, 9: Q04034

33 Sun J M, Lu T Y, Zhang Z Q, et al. Stepwise expansions of $\mathrm{C}_{4}$ biomass and enhanced seasonal precipitation and regional aridity during the Quaternary on the southern Chinese Loess Plateau. Quat Sci Rev, 2012, 34: 57-65

34 Wang X S, Yang Z Y, Løvlie R, et al. Environmental magnetism and paleoclimatic interpretation of the Sanmenxia loess-paleosol sequence in the southeastern extremity of the Chinese Loess Plateau. 
Chin Sci Bull, 2006, 51: 2755-2762

35 Nie J S, Song Y G, King J W, et al. HIRM variations in the Chinese red-clay sequence: Insights into pedogenesis in the dust source area. J Asian Earth Sci, 2010, 38: 96-104

36 Chen J, An Z S, Liu L W, et al. Variations in chemical compositions of the eolian dust in Chinese Loess Plateau over the past $2.5 \mathrm{Ma}$ and chemical weathering in the Asian inland. Sci China Ser D, 2001, 44: 403-413

37 Sun J M. Nd and $\mathrm{Sr}$ isotopic variations in Chinese eolian deposits during the past $8 \mathrm{Ma}$ : Implications for provenance change. Earth Planet Sci Lett, 2005, 240: 454-466

38 Ao H, Dekkers M J, Deng C L, et al. Palaeoclimatic significance of the Xiantai fluvio-lacustrine sequence in the Nihewan Basin (North China), based on rock magnetic properties and clay mineralogy. Geophys J Int, 2009, 177: 913-924

39 Ao H. Mineral-magnetic signal of long-term climatic variation in Pleistocene fluvio-lacustrine sediments, Nihewan Basin (North China). J Asian Earth Sci, 2010, 39: 692-700
40 Sun J M, Liu T S. Stratigraphic evidence for the uplift of the Tibetan Plateau between $\sim 1.1$ and $~ 0.9$ Ma ago. Quat Res, 2000, 54: 309-320

41 An Z S, Zhang P Z, Wang E C, et al. Changes of the monsoon-arid environment in China and growth of the Tibetan Plateau since the Miocene (in Chinese). Quat Sci, 2006, 26: 678-693

42 Liu D L, Fang X M, Song C H, et al. Stratigraphic and paleomagnetic evidence of mid-Pleistocene rapid deformation and uplift of the NE Tibetan Plateau. Tectonophysics, 2010, 486: 108-119

$43 \mathrm{Wu} \mathrm{B}, \mathrm{Wu} \mathrm{N}$ Q. Terrestrial mollusk records from Xifeng and Luochuan L9 loess strata and their implications for paleoclimatic evolution in the Chinese Loess Plateau during marine Oxygen Isotope Stage 24-22. Clim Past, 2011, 7: 349-359

44 Ding Z L, Debryshire E, Yang S L, et al. Stepwise expansion of desert environment across northern China in the past $3.5 \mathrm{Ma}$ and implications for monsoon evolution. Earth Planet Sci Lett, 2005, 237: 45-55

45 Wu F L, Fang X M, Ma Y Z, et al. Plio-Quaternary stepwise drying of Asia: Evidence from a 3-Ma pollen record from the Chinese Loess Plateau. Earth Planet Sci Lett, 2007, 257: 160-169

Open Access This article is distributed under the terms of the Creative Commons Attribution License which permits any use, distribution, and reproduction in any medium, provided the original author(s) and source are credited. 